\title{
Evaluation of a filtration-based method for detecting Batrachochytrium dendrobatidis in natural bodies of water
}

\author{
Oliver J. Hyman*, James P. Collins \\ Arizona State University, School of Life Sciences, 427 E. Tyler Mall, LSC 410, Tempe, Arizona 85287, USA
}

\begin{abstract}
Infectious diseases are emerging as a significant threat to wildlife. The resulting increased effort to monitor wildlife diseases is driving the development of innovative pathogen monitoring techniques, including many polymerase chain reaction (PCR)-based diagnostics. Despite the utility of these PCR-based techniques, there is still much to be learned about their ability to accurately detect target pathogens in nature. We assessed the diagnostic sensitivity of a PCR-based water filtration technique to detect the directly transmitted aquatic fungal pathogen Batrachochytrium dendrobatidis $(B d)$ by comparing the results of 4 repeated filter sampling events from 20 ponds to those of skin swabs from ca. 60 boreal chorus frogs Pseudacris maculata from each pond. Filters failed to detect $B d$ in 31 to $77 \%$ of the swab-positive ponds, depending on the time of sampling. However, after 3 repeated sampling events, filtration of small volumes of water (ca. $600 \mathrm{ml}$ ) correctly identified $94 \%$ of the ponds that tested $B d$ positive with swabbing, with the highest rates of detection occurring after breeding but before larvae reached metamorphosis. Our results are a case study demonstrating the importance of timing and resampling for the detection of an aquatic microbial pathogen, $B d$, from water. This will be a useful technique for monitoring $B d$, but additional data are needed to test the degree to which our findings are species or population specific. Future studies need to examine the sensitivity of this technique in other habitats and species that host $B d$. These studies will aid in the development of cost-effective monitoring regimes for $B d$ and potentially other aquatic pathogens.
\end{abstract}

KEY WORDS: Amphibian chytrid - Environmental monitoring · Detection · Pathogen · Chytridiomycosis $\cdot \mathrm{qPCR} \cdot$ Pseudacris

Resale or republication not permitted without written consent of the publisher

\section{INTRODUCTION}

Infectious diseases are emerging as a significant threat to wildlife (Daszak et al. 2000). Understanding this threat necessitates the development of innovative monitoring techniques that can increase the accuracy and efficiency of pathogen surveys. Surveys of wildlife pathogens are often limited by time, money, host species abundance, and ethical issues related to invasive animal-sampling techniques (Spalding \& Forrester 1993). Environmental detection of pathogens has the potential to greatly reduce these ethical and logistical constraints by removing the need to capture host species (e.g. Kirshtein et al. 2007). Environmental sampling can also enrich our understanding of pathogen dynamics outside of their central hosts (e.g. Epstein 1993, Walker et al. 2007). For these reasons, DNA screening of environmental samples has been used to detect a number of waterand soil-borne pathogens of humans (e.g. Loge et al. 2002) and wildlife (e.g. Brinkman et al. 2003, Audemard et al. 2004). Advances in DNA purification and amplification have enabled the development of highly specific and analytically sensitive environ- 
mental diagnostics (e.g. Kirshtein et al. 2007). However, without knowledge of the rates at which these assays miss the presence of a target pathogen, disease prevalence estimates can be greatly underestimated, negating the aforementioned advantages and misleading scientists and managers (e.g. Greer \& Collins 2007). It is, therefore, critically important to thoroughly assess the sensitivity of these diagnostics.

A diagnostic assay's sensitivity has 2 components: analytical sensitivity and diagnostic sensitivity. Analytical sensitivity is the smallest amount of a substance in a sample that can be measured accurately by an assay. Diagnostic sensitivity is the percentage of samples that have the target substance that are properly identified by the assay (Saah \& Hoover 1997). The sensitivity of DNA-based diagnostics for soil- and water-borne pathogens is influenced by a number of factors, including the volume of sample processed, the efficiency of target recovery, and the presence of polymerase chain reaction (PCR)inhibitory compounds (Loge et al. 2002). Variation in these factors will influence the overall diagnostic sensitivity of the assay, potentially resulting in false negatives (lack of detection despite the presence of the pathogen). This, in turn, will influence the interpretation of sampling results, with the potential to underestimate pathogen prevalence and distribution. Here, we assess the diagnostic sensitivity and advantages of a novel PCR-based water filtration technique for the detection of an emerging aquatic fungal pathogen, Batrachochytrium dendrobatidis $(B d)$.

$B d$ is a member of the fungal phylum Chytridiomycota (chytrids). Like other chytrids, $B d$ is transmitted by flagellated propagules called zoospores (Berger et al. 1998, 2005). These zoospores travel through water to encyst in the outermost layers of keratinized amphibian host skin cells. Once encysted, the zoospores develop into zoosporangia that eventually open, releasing more infective zoospores into the environment (Berger et al. 2005). Heavy Bd infections can result in chytridiomycosis, a disease in which amphibians lose their ability to osmoregulate due to the inhibition of cutaneous ion exchange (Voyles et al. 2009).

Chytridiomycosis is linked to declines and extinctions of ca. 200 species of frogs on several continents (Collins \& Crump 2009). In response to this emerging infectious disease, international and governmental agencies on several continents are investing millions of dollars in research and development of amphibian threat abatement plans, which include guidelines to describe the distribution and understand the epidemiology of chytridiomycosis (Skerratt et al. 2007,
USFWS 2007). These, along with other Bd-monitoring initiatives, make clear the need for time- and cost-effective tools that can accurately monitor $B d$ in the field.

One such tool is filtering water to detect $B d$ in the aquatic environment (Kirshtein et al. 2007, Walker et al. 2007). This technique is designed to capture zoospores or remnant $B d$ DNA from the water column and then amplify this DNA using PCR. These filtration techniques have the potential to significantly reduce $B d$ sampling effort and costs by eliminating the need to collect and process DNA samples from the currently accepted standard of 30 to 60 animals per habitat, which can be difficult to obtain when dealing with sites with low amphibian abundance or rare or cryptic species (Skerratt et al. 2008). Recent studies (Kirshtein et al. 2007, Walker et al. 2007) successfully detected $B d$ from small volumes $(<1$ l) of field-collected water using a highly specific PCRbased assay (Hyatt et al. 2007). They also found these techniques to have a high analytical sensitivity, with detection limits as low as 0.1 zoospores (Walker et al. 2007) and 0.06 zoospores (Kirshtein et al. 2007). Yet, we do not know the overall diagnostic sensitivity of these filtration techniques, nor do we clearly understand the factors that enhance the likelihood of $B d$ detection by filtration.

Our goal was to assess the ability of water filters to correctly identify a pond as $B d$ positive by comparing filter outcomes to those of the currently accepted standard of skin swabs from 60 frogs. Although swabs from 60 animals cannot definitively confirm the absence of $B d$ from these ponds, this method currently serves as the most accurate way to determine the presence of $B d$ within a habitat, with $95 \%$ certainty if prevalence is $\geq 5 \%$ (Skerratt et al. 2008). Using 20 ephemeral ponds with $B d$-infected populations of the boreal chorus frog Pseudacris maculata, we addressed the following questions: (1) What percentage of filters fails to detect $B d$ when present in swabs collected from live animals? (2) How many filters should be taken to maximize the probability of detecting $B d$ ? (3) When is the ideal time to filter water to maximize $B d$ detection?

\section{MATERIALS AND METHODS}

\section{Field sites and focal amphibian host species}

Water samples and skin swabs were collected from each of 20 ponds in Coconino National Forest, Coconino County, Arizona, USA. All ponds were 
lentic bodies of water: ephemeral ponds, perennial ponds, man-made cattle ponds, and 1 spring. Ponds ranged in elevation from 1700 to $2400 \mathrm{~m}$, with a mean maximum surface area of 2.3 ha (SEM: $\pm 1.2 \mathrm{ha}$; limits: 0.15 to $24 \mathrm{ha}$ ), and a mean maximum depth of $180 \mathrm{~cm}$ (SEM: $\pm 50 \mathrm{~cm}$; limits: 68 to $250 \mathrm{~cm}$ ).

Skin swabs were collected from breeding adult boreal chorus frogs Pseudacris maculata. This species is an annual spring breeder. In Arizona, adult males aggregate in dense choruses at shallow ends of ponds and conduct mating calls for several weeks following snowmelt in late February to early April. Tadpoles develop over a ca. 2.5 mo period, with metamorphic frogs typically emerging when ponds begin to dry in mid-June. Adults and metamorphic frogs forage near pond edges during the summer and overwinter under leaves, rocks, and logs beneath the snow (O. Hyman unpubl. data). Over this lifecycle, chorus frogs may migrate a maximum of $200 \mathrm{~m}$ from their natal pond (Kramer 1973). We, therefore, considered our study ponds to be independent populations as they were separated by a minimum of $1 \mathrm{~km}$.

\section{Animal sampling}

From March to May 2010, we swabbed ca. 60 adult frogs from each pond, for a total of 1115 swabs. Approximately 30 adult frogs were collected from each pond during each of 2 time periods: (1) when breeding was initiated (T1) and (2) 1 to 2 wk postbreeding initiation (T2; Fig. 1). These 2 time periods were selected to maximize the likelihood of detecting $B d$, as $B d$ prevalence is highest in adult frogs and these are the only times when they are easily obtained (O. Hyman unpubl. data). All animals were swabbed between 19:00 and 01:00 h. Animals were captured by hand, wearing disposable vinyl gloves, which were changed after handling each individual to prevent the spread of $B d$. Each frog was swabbed with a wooden toothpick, toe-clipped to prevent

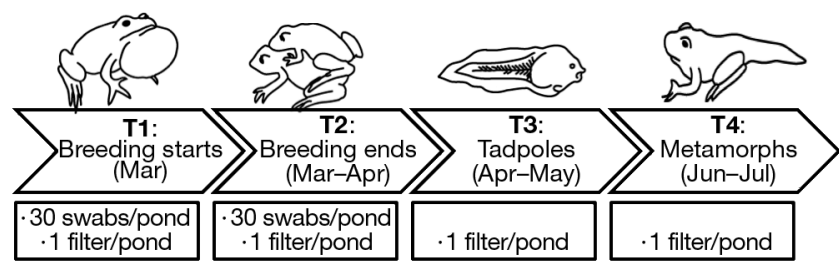

Fig. 1. Timeline of pathogen sampling strategy from 20 ponds in relationship to the lifecycle stages of the boreal chorus frog Pseudacris maculata resampling, and released at the site of capture (Retallick et al. 2006). Swabs were placed in individual $2 \mathrm{ml}$ screw-cap microcentrifuge tubes (USA Scientific, No. 1420-9701) containing 70\% ethanol. In addition, an unused swab was placed into a tube at each site to act as a negative field control. All vials were kept on ice then stored at $-20^{\circ} \mathrm{C}$ in the laboratory. All field equipment was rinsed with $20 \%$ bleach solution and completely dried between collecting events to prevent contamination across sites. Swabs were extracted in Prepman Ultra (Applied Biosystems, Part No. 4318903), diluted 1:10 in sterile water, and stored at $-20^{\circ} \mathrm{C}$ in preparation for PCR analysis following Retallick et al. (2006). Bd-positive and -negative controls were included in each extraction batch.

\section{Water sampling}

Water filters were collected from each pond at 4 different time points (Fig. 1): T1 and T2 as already described, T3 (3 to 4 wk post-breeding initiation, when tadpoles were present), and T4 (10 wk postbreeding initiation when metamorphosed froglets began to emerge). These time points were selected to maximize the likelihood of $B d$ detection by matching the times of highest density for each chorus frog life stage. Swabs of larval and newly metamorphosed frogs were not obtained due to monetary constraints and failure to detect $B d$ infections in these life stages in previous surveys (O. Hyman unpubl. data).

One filter was collected from each pond at each time point, unless ponds had dried, in which case no filters were collected (Table 1). Water was filtered following Kirshtein et al. (2007). Briefly, water from each pond was pushed through an individual Sterivex $0.22 \mu \mathrm{m}$ filter (Millipore Part No. SVGV01015) using a sterilized $60 \mathrm{ml}$ Luer-Lok plastic syringe (BD, Part No. 309653). New syringes and filters were used for each pond. After the sample was filtered, $60 \mathrm{ml}$ of phosphate-buffered saline (PBS) was pushed through the filter. Then each filter was drained, labeled, sealed in an individual Ziplok bag, and kept on ice for $\leq 5 \mathrm{~h}$ until it could be frozen at $-20^{\circ} \mathrm{C}$ in preparation for DNA extraction. A total of ca. $600 \mathrm{ml}$ of water was filtered from each pond by collecting $20 \mathrm{ml}$ from 30 locations within $3 \mathrm{~m}$ of pond edges. Samples were spaced evenly along the entire pond circumference, but taken only from areas where frogs or tadpoles were present. To account for potential heterogeneity in the distribution of $B d$ in the water column, we sampled water from a variety of within-pond microhabitats including areas of 
Table 1. Batrachochytrium dendrobatidis (Bd). Results of swabs of Pseudacris maculata and filters taken from 20 ponds on the Mogollon rim, Arizona, USA. Percent of swab-positive ponds $(n=17)$ testing $B d$ positive by filtration when ponds with potential false negative results were removed from analyses (i.e. Baker Lake and No Name 13); only 16 ponds tested $B d$ positive by swabs at T1 (data not shown). BS: breeding starts; BE: breeding ends; Tad: tadpoles; Meta: metamorphs. T1: initiation of breeding; T2: 1 to 2 wk post-breeding; T3: 3 to 4 wk post-breeding; T4: 10 wk post-breeding; na: missing samples

\begin{tabular}{|c|c|c|c|c|c|c|c|c|c|}
\hline \multirow{2}{*}{ Pond } & \multicolumn{3}{|c|}{- Swabs } & \multirow[b]{2}{*}{$\begin{array}{c}\text { T1 } \\
\text { (BS) }\end{array}$} & \multirow[b]{2}{*}{$\begin{array}{c}\mathrm{T} 2 \\
(\mathrm{BE})\end{array}$} & \multirow[b]{2}{*}{$\begin{array}{l}\text { T3 } \\
\text { (Tad) }\end{array}$} & \multirow{2}{*}{$\begin{array}{c}\text { Filters } \\
\text { T4 } \\
\text { (Meta) }\end{array}$} & \multirow[b]{2}{*}{$\begin{array}{l}\text { Filters } \\
\text { overall }\end{array}$} & \multirow[b]{2}{*}{$\begin{array}{l}\text { Total no. of } \\
\text { positive filters }\end{array}$} \\
\hline & $B d$ status & $\mathrm{N}$ & $\%$ infected & & & & & & \\
\hline 27 Mile Lake & + & 60 & 67 & + & + & - & - & + & 2 \\
\hline Alder Lake & + & 60 & 38 & - & + & + & - & + & 2 \\
\hline Aspen Lake & + & 60 & 98 & + & + & + & - & + & 3 \\
\hline Baker Lake ${ }^{a}$ & - & 31 & 0 & - & - & - & na & - & 0 \\
\hline Bar D Tank & + & 60 & 58 & + & + & - & - & + & 2 \\
\hline Brolliar Park Tank & + & 60 & 22 & - & + & + & + & + & 3 \\
\hline Brolliar Wetland & + & 60 & 35 & na & + & na & - & + & 1 \\
\hline Calloway Lake & + & 60 & 43 & + & + & + & - & + & 3 \\
\hline Clints Lake & + & 60 & 12 & + & - & - & + & + & 2 \\
\hline Mahan Park & + & 47 & 15 & - & - & + & + & + & 2 \\
\hline McClure Lake & + & 57 & 7 & - & - & - & na & - & 0 \\
\hline Mud Tank & - & 60 & 0 & - & - & - & - & - & 0 \\
\hline No Name $13^{a}$ & - & 25 & 0 & + & - & - & - & + & 1 \\
\hline No Name 7 & + & 51 & 59 & - & + & - & na & + & 1 \\
\hline Salmon Lake & + & 55 & 75 & - & - & + & - & + & 1 \\
\hline Tbar 2 & + & 60 & 32 & - & - & + & - & + & 1 \\
\hline Tinny Tank & + & 60 & 30 & - & + & + & na & + & 2 \\
\hline Twin Ponds & + & 70 & 10 & - & - & + & - & + & 1 \\
\hline Van Deren Spring & + & 60 & 25 & - & + & + & na & + & 2 \\
\hline Allen Park Tank & + & 59 & 22 & - & + & + & - & + & 2 \\
\hline Total & 17 & 1115 & - & 6 & 11 & 11 & 3 & 17 & 31 \\
\hline$\% B d$ positive ${ }_{\text {all ponds }}$ & 85 & 34 & - & 32 & 55 & 58 & 20 & 85 & 42 \\
\hline$\%$ of swab-positive ponds & s 100 & - & - & $0.31^{b}$ & 0.65 & $0.69^{b}$ & $0.23^{\mathrm{b}}$ & 94 & 48 \\
\hline
\end{tabular}

dense/sparse vegetation, detritus, and amphibian densities. Volumes filtered were recorded when filters became clogged prior to $600 \mathrm{ml}$. DNA was extracted from filters following the protocol developed by Kirshtein et al. (2007).

\section{Real-time TaqMan PCR assay}

Samples were run in duplicate using an Applied Biosystems 7900HT sequence detection system and a modified version of the protocol developed by Boyle et al. (2004) and Garland et al. (2010). To reduce costs, we used $20 \mu \mathrm{l}$ (rather than $25 \mu \mathrm{l}$ ) reactions containing $10 \mu \mathrm{l}$ of $2 \times$ TaqMan Universal PCR Master Mix (Applied Biosystems, Part No. 43034437), $1 \mu \mathrm{l}$ of $18 \mu \mathrm{M}$ primers, $0.5 \mu \mathrm{l}$ of $5 \mu \mathrm{M}$ TaqMan probe, $2.5 \mu \mathrm{l}$ of sterile DNA grade water, $8 \mu \mathrm{g}$ of bovine serum albumin (BSA), and $5 \mu \mathrm{l}$ of the previously described sample. This master cocktail was split into 2 tubes, one of which received TaqMan exogenous internal positive control (IPC; Applied Biosystems, Part No. 43083283) following Garland et al. (2010). The other tube was left as 'normal' master mix. One duplicate of each sample contained IPC to test for PCR inhibition. In addition, 3 wells containing IPC and DNAgrade sterile water for template served as IPC controls. Standards of 20.0, 2.0, 0.2, and $0.02 B d$ genome equivalents (GE) $\mu^{-1}$ (equivalent to $100,10,1$, and $0.1 \mathrm{GE}$ in the total $5 \mu \mathrm{l}$ of template added) and negative controls were included in each 384-well plate.

\section{Analysis}

Following Garner et al. (2009), samples were scored positive if both duplicate wells were positive by quantitative PCR (qPCR). If 1 or none of the duplicate wells tested $B d$ positive, the sample was rerun in duplicate. If 2 or more of the 4 wells tested $B d$ positive over the course of these runs, the sample was considered $B d$ positive. If none of the wells tested positive in 
this rerun and there were no signs of PCR inhibition, the samples were considered $B d$ negative, with any previous single positive wells considered the result of inadvertent contamination or background fluorescence (Kriger et al. 2006). Following Garner et al. (2009), samples were considered PCR-inhibited if IPC cycle thresholds $\left(C_{\mathrm{T}}\right.$ values) were $>2$ cycles above IPC $C_{\mathrm{T}}$ of the sterile water controls. Negative samples with IPC $C_{\mathrm{T}}>2 C_{\mathrm{T}}$ values over the controls were rerun in duplicate. They were counted as negative if they came back with IPC $C_{\mathrm{T}}$ values $\leq 2 C_{\mathrm{T}}$ over the controls. If negative samples still showed signs of inhibition after the rerun, they were rerun in duplicate a third time at a 10-fold dilution and counted as negative or positive following the criteria above.

The amount of $B d$ DNA in filter extract, in GE units, was calculated as:

Zoospore GE = mean output of all $B d$-positive wells $\times 200$

to account for sample dilutions and unit conversions. Results from 10-fold diluted samples were multiplied by an additional factor of 10 . Zoospore GE $\mathrm{l}^{-1}$ was calculated as:

\section{Zoospore GE $\mathrm{l}^{-1}=($ zoospore GE/volume filtered $[\mathrm{ml}]) \times 1000$}

Filter sensitivity was calculated within each individual sampling period by dividing the number of ponds testing $B d$ positive by filtration by those testing positive by swabbing, with the following caveats. Ponds testing $B d$ negative by swabbing $<60$ animals were dropped from calculations of filter sensitivity because they run a $>5 \%$ risk of being false negatives (Skerratt et al. 2008). We also assumed that, because amphibian hosts were present in ponds throughout our sampling periods and $B d$ has persisted in these ponds for multiple years (O. Hyman unpubl. data), it is unlikely that $B d$ would completely disappear from any $B d$-positive pond during the time periods we sampled. Furthermore, a pond testing $B d$ positive at any time point by swabbing, should be considered a $B d$-positive location. Therefore, all ponds that tested $B d$ positive by swabbing by the end of the breeding season (T2) were assumed to be $B d$ positive throughout the following sampling periods (T3 and T4). We considered any filter testing negative from these ponds to be a false negative, and calculated the probability of a false negative $(P)$ as:

$$
\begin{gathered}
P=1-(\text { no. of } B d+\text { ponds by filter } \\
\text { pond } n \text { ho. of } B d+ \\
\text { ponab } \left.\operatorname{swab}_{\mathrm{T} n}\right)
\end{gathered}
$$

where $\mathrm{T}_{n}=$ the time period of sampling.
Filter sensitivity relative to swabs was also calculated across all sampling periods by dividing the cumulative number of ponds testing $B d$ positive with filtration by the number of swab-positive ponds. Lastly, we calculated the overall sensitivity of filters (i.e. the percent of $B d$-positive ponds by swabbing that were correctly identified across each sampling period) for every possible combination of $1,2,3$, and 4 sampling events. These percentages were used to determine the mean, minimum, and maximum sensitivity of filters after 1, 2, 3, and 4 sampling events. These percentages were also used to identify the most time-effective combination of sampling periods to filter water in order to maximize detection while minimizing sampling effort. Bonferroni-corrected Spearman rank correlations were used to explore the relationship between $B d$ prevalence within a pond and the total number of filters testing $B d$ positive within that pond. Linear regression was used to compare log-transformed zoospore GE from $B d$-positive filters to log-transformed volume of pond water filtered. Log-transformed zoospore densities detected by filters were compared across sampling periods using a non-parametric Kruskal-Wallis test to account for small sample sizes and zero inflation. All statistics were performed in JMP (Ver. 5.0.1.2, SAS).

\section{RESULTS}

\section{Swabs}

Sixty swabs were collected from all except 7 ponds (Table 1). Two ponds with total sample sizes $<60$ (Baker Lake, $\mathrm{n}=31$, and No Name 13, $\mathrm{n}=25$ ) also tested $B d$ negative with swabs, and were therefore omitted from our calculations comparing filters to swabs (see justification above; Table 1). Swabs detected $B d$ at 16 of 20 ponds (80\%) when breeding began ( $\mathrm{T} 1$; data not shown). Swabs detected $B d$ at the same 16 ponds as well as 1 additional pond (Twin) at T2, for a total of 17 of 20 ponds testing $B d$ positive (85\%; Table 1). Bd prevalence at each pond varied from 0 to $98 \%$ (mean $=32 \%, \mathrm{SD}=27 \%$; Table 1). Despite high $B d$ prevalence, no mass mortalities were observed.

\section{Filters}

Filters were collected in all 4 time periods for all but 6 ponds, which either dried completely before the final sampling was finished or had lost samples 
(Table 1). The mean volume of water filtered across all ponds within each time period was significantly

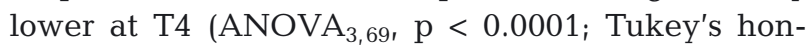
estly significant difference $\left.[\mathrm{HSD}]_{\alpha=0.05}\right)$, with mean $( \pm$ SEM) volumes of $510( \pm 32), 513( \pm 31), 545( \pm 32)$, and $297( \pm 36) \mathrm{ml}$ filtered at T1, T2, T3, and T4, respectively. This reduction in filtrate at $\mathrm{T} 4$ was due to increased water turbidity as ponds dry during the course of the summer.

PCR inhibition was minimal in our samples. Only 11 negative samples had IPC $C_{\mathrm{T}}>2$ cycles above sterile water controls. All of these samples tested negative for $B d$ after reruns and dilutions that brought IPC $C_{\mathrm{T}}$ within 2 cycles of controls $\left(C_{\mathrm{T}}=33\right)$. IPC $C_{\mathrm{T}}$ values of all other negative samples ranged from -1 to 2 cycles above control IPC $C_{\mathrm{T}}$ values, with a mean of 1 cycle above controls. Although we cannot rule out inhibition as the reason $B d$ was not detected in the samples that had IPC $C_{\mathrm{T}}$ values $>0$ cycles above IPC controls ( $\mathrm{n}=15)$, the fact that the IPCs in these samples amplified within 2 cycles of controls indicates that, although there were inhibitors present in these samples, they did not significantly reduce or preclude DNA amplification. We, therefore, considered these to be true negatives. All positive and negative extraction and field controls worked properly.

Filters were able to detect $B d$ in every pond with $B d$ prevalence $\geq 10 \%$ in amphibian hosts (Table 1 ). Overall, filters produced results similar to swabs, with 17 of 20 ponds ( $85 \%$ ) testing $B d$ positive by filtration (Table 1). However, these were not the exact same 17 ponds that tested positive by swabbing. One $B d$-negative pond by swab tested $B d$ positive by filtration (No Name 13) and vice versa (McClure; Table 1). The pond testing $B d$ positive by filtering, but not swabbing, had our smallest sample size, with 25 swabbed animals (Table 1). The pond testing $B d$ positive by swabbing, but not filtering, had the lowest $B d$ prevalence $(7 \%)$ of all ponds tested (Table 1$)$. The overall number of filters testing positive within a pond was positively correlated with the prevalence of $B d$ in adult chorus frogs that bred there (Spearman's rho $=0.48, \mathrm{p}=0.03$ ), indicating that higher prevalence in breeding adults at the start of the season increases the likelihood of $B d$ detection by filters throughout chorus frog breeding and development. The mean density of aquatic zoospores across only positive filters $(\mathrm{n}=31)$ was 30.0 zoospore $\mathrm{GE} \mathrm{l}^{-1}$ (SEM: 10.8 ; limits: 1.3 to 313 zoospore GE $1^{-1}$ ). Mean $( \pm$ SEM) zoospore densities increased from $5.4( \pm 2.7)$ to $20.2( \pm 15.5)$ zoospore $\mathrm{GE} \mathrm{l}^{-1}$ from $\mathrm{T} 1$ to $\mathrm{T} 2$ then decreased to $14.0( \pm 5.9)$ and $10.4( \pm 8.8)$ zoospore GE

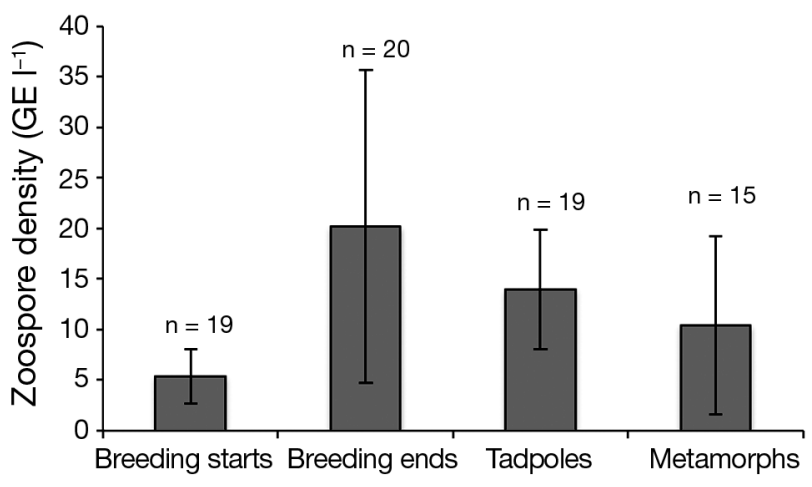

Fig. 2. Batrachochytrium dendrobatidis $(B d)$. Mean ( \pm SEM) density of $B d$ zoospore genome equivalents (GE) $l^{-1}$ detected in water filters taken from 20 chorus frog Pseudacris maculata breeding ponds at 4 different time points related to frog breeding and development. No significant differences were found (Kruskal-Wallis $\chi^{2}{ }_{3}=5.8,=0.12$ )

$\mathrm{1}^{-1}$ at T3 and T4, respectively (Fig. 2). However, there was no significant difference in the detected zoospore densities across sampling time periods (Kruskal-Wallis $\chi^{2}{ }_{3}=5.8,=0.12$ ). There was no relationship between the number of zoospore GE detected in $B d$-positive filters and the volume of water filtered (linear regression adjusted $r^{2}=0.001$, $F_{1,29}=0.03, \mathrm{p}=0.86$ ); however, we filtered a narrow range of water volumes (240 to $600 \mathrm{ml}$ ), which limits the interpretation of this result.

Two ponds (Baker Lake and No Name 13) were dropped from our sensitivity analyses due to $B d$ negative results and insufficient sampling of animals at the start of the breeding season (see criteria for dropping above; Table 1). These ponds were excluded from all calculations in the following paragraph. Of the remaining 18 ponds that met our inclusion criteria, 17 tested $B d$ positive by swabbing (94\%; Table 1, Figs. 3 \& 4). After 4 sampling events, filters failed to detect $B d$ from only 1 of these 17 ponds that tested $B d$ positive by swabbing (McClure Lake; Table 1, Fig. 4). However, filter-positive ponds did not consistently test positive across all filter sampling events. In fact, 32 of the $62(52 \%)$ total filters taken from ponds that were known to be $B d$ positive by swabs $(\mathrm{n}=17)$ tested $B d$ negative (Table 1). The percentage of $B d$-positive ponds by swab ( $\mathrm{n}=17)$ that tested $B d$ positive by filtration was 31 (T1), 65 (T2), 69 (T3), and 23 (T4) within each sampling event (Table 1). This translates to a false negative rate varying from 31 to $77 \%$ within a single sampling period, with the most false negatives occurring at $\mathrm{T} 1$ and $\mathrm{T} 4$ (Fig. 3). The cumulative percent of swab-positive 


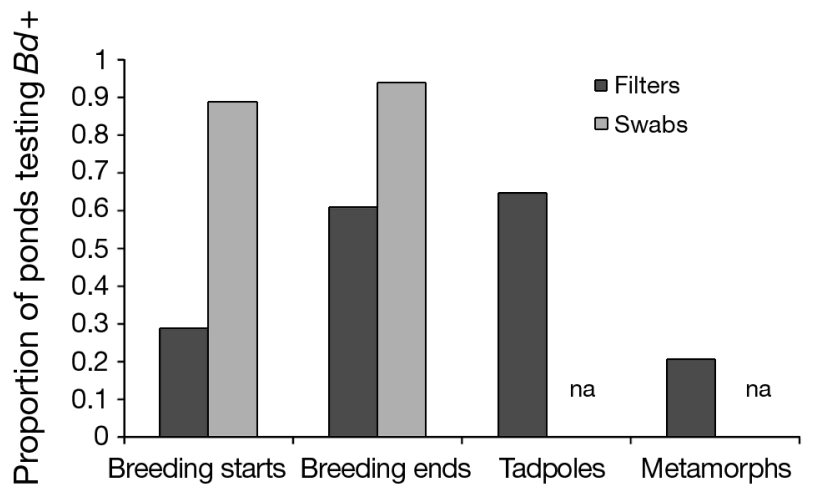

Fig. 3. Proportion of ponds $(n=18)$ testing positive for the presence of Batrachochytrium dendrobatidis $(B d)$ at 4 different time points in the life cycle of boreal chorus frogs Pseudacris maculata by 2 sampling methods: filtration of $600 \mathrm{ml}$ of pond water and swabbing $\geq 47$ animals. (Two ponds were dropped from these analyses because an insufficient number of animals were swabbed from these ponds to have $95 \%$ confidence in their disease status.) When swabs were collected, they consistently detected $B d$ in a greater number of ponds than filters (swabs were not collected from tadpoles or metamorphs). na: not applicable

ponds that tested positive by filtration increased from 31 to 71 to $94 \%$ after 1, 2, and 3/4 sampling events, respectively (Fig. 4). This translates to 69, 29 , and $6 \%$ of swab-positive ponds falsely testing negative by filtration after 1,2 , and $3 / 4$ filter sampling events, respectively.

Including all ponds, regardless of swab sample size, a total of 18 ponds tested $B d$ positive by either swabbing or filtering. At the 2 time points when both swabs and filters were taken (T1 and T2) swabbing ca. 30 adult host animals (T1) detected $B d$ in 16 of the $18 B d$-positive ponds (89\%) and swabbing ca. 60 animals (T1 and T2) detected $B d$ in 17 of the $18 B d$-positive ponds (94\%), while filtering detected $B d$ in only

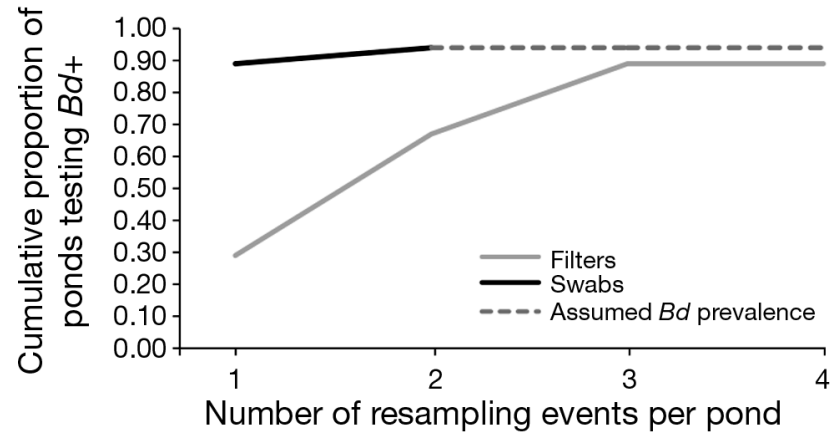

Fig. 4. Cumulative proportion of ponds $(\mathrm{n}=18)$ testing positive for the presence of Batrachochytrium dendrobatidis $(B d)$ by water filtration and swabbing of boreal chorus frogs Pseudacris maculata. (Two ponds were dropped from these analyses because an insufficient number of animals were swabbed from these ponds to have $95 \%$ confidence in their disease status.) Ponds that tested positive by swabbing were considered $B d$ positive throughout the course of sampling; $95 \%$ of ponds tested $B d$ positive after 2 swabbing events. After 3 resampling events, filters were able to detect $B d$ in 16 of the 17 ponds (94\%) testing $B d$ positive by swabbing ca. 60 animals

$6(33 \%)$ and $11(61 \%)$ of the 18 known $B d$-positive ponds at $\mathrm{T} 1$ and $\mathrm{T} 2$, respectively.

Repeated water sampling at key time periods related to the life stages and natural history of our study species corrected this lack of detection. Filtering water at all 4 time points (T1 to $\mathrm{T} 4$ ) detected $B d$ at 17 of the 18 ponds that tested $B d$ positive by swabs or filters (94\%; Table 2). Examining every permutation of filter sampling regimes revealed that filtering at only 3 time points would have detected $B d$ at 14 to 17 ponds ( 78 to $94 \%$ ), filtering at only 2 time points would have detected $B d$ at 8 to 15 ponds (44 to $83 \%$ ), and filtering at only 1 time point would have detected $B d$ at 3 to

Table 2. Batrachochytrium dendrobatidis $(B d)$. Evaluation of the role of resampling in the detection of $B d$ using filters of water from boreal chorus frog Pseudacris maculata breeding ponds. Every possible combination of sampling was examined to identify the survey regime that maximizes the likelihood of $B d$ detection (ideal resampling schedule). Increasing the number of sampling events was vital for increasing the number of ponds where $B d$ was detected by water filtration. The maximum percent of ponds testing falsely negative was calculated by subtracting the minimum percent of $B d+$ ponds $(\mathrm{n}=18)$ detected by each sampling regime from 100. T1-T4 defined in Table 1

\begin{tabular}{|c|c|c|c|c|}
\hline $\begin{array}{l}\text { No. of filter } \\
\text { sampling events }\end{array}$ & $\begin{array}{l}\text { Mean no. } B d+\text { ponds detected } \\
\text { by filters (min.-max.) }\end{array}$ & $\begin{array}{l}\% B d+\text { ponds detected } \\
\text { by filters }{ }^{\mathrm{a}} \text { (min.-max.) }\end{array}$ & $\begin{array}{l}\text { Max. \% of ponds } \\
\text { testing falsely negative }\end{array}$ & $\begin{array}{l}\text { Ideal resampling } \\
\text { schedule }\end{array}$ \\
\hline 1 & $8(3-11)$ & $17-61$ & 83 & $\mathrm{~T} 2$ or $\mathrm{T} 3$ \\
\hline 2 & $13(8-15)$ & $44-83$ & 56 & $\mathrm{~T} 2+\mathrm{T} 3$ or $\mathrm{T} 1+\mathrm{T} 3$ \\
\hline 3 & $16(14-17)$ & $78-94$ & 22 & $\mathrm{~T} 1, \mathrm{~T} 2, \mathrm{~T} 3$ \\
\hline 4 & 17 & 94 & 6 & $\mathrm{~T} 1, \mathrm{~T} 2, \mathrm{~T} 3, \mathrm{~T} 4$ \\
\hline
\end{tabular}


11 ponds (17 to $61 \%$ ) depending on the timing of sampling (Table 2).

\section{DISCUSSION}

Detecting pathogens by water filtration has several clear advantages over sampling animals. First, sampling water eliminates many ethical concerns related to the harm and stress caused during the sampling of animal hosts. Second, filtration enables pathogen detection in the absence of a sufficient number of animal hosts. These advantages are especially important when working with cryptic, rare, or endangered species (e.g. USFWS 2007). Third, filtering can reduce the time and money spent to detect a target organism in the field by reducing the number of samples needed to accurately detect a pathogen (Skerratt et al. 2008). However, all of these advantages depend on the sensitivity of the filtration technique.

We found that sampling small volumes of pond water for $B d$ had a low diagnostic sensitivity at individual time points. Overall, 31 to $77 \%$ of filters failed to correctly identify $B d$ swab-positive ponds in any single sampling period. This is an unacceptable level of sensitivity to determine the presence or absence of a target pathogen (Pfeiffer 2002). Despite the low sensitivity of our filters in individual sampling periods, our finding of $94 \%$ (16 of 17 ponds) agreement between filters and swabs after 3 sampling events and an equal number of $B d$-positive ponds $(\mathrm{n}=17)$ being detected by 60 swabs and 3 filtering events demonstrates that, with proper resampling, filters can be a viable $B d$ monitoring technique in our system.

Matches between sample IPCs and controls indicate the reduced filter sensitivity in individual sampling periods is unlikely to be caused by PCR inhibition. It is more likely that $B d$ is either not present in the small volume of water that was sampled or present at densities below detection. Increasing the volume of filtrate by prefiltering water with a more coarse filter or switching to slightly larger pore sizes that will still capture zoospores (e.g. $45 \mu \mathrm{m})$ may increase the chance of detection.

Our finding of $94 \%$ (16 of 17 ponds) agreement between filters and swabs after 3 sampling events demonstrates the importance of sampling a pond multiple times in order to detect $B d$ by water filtration (Fig. 4). Although sampling all 3 filters in one time period could greatly reduce effort and expenses related to revisiting sites, the highest percentage of filters detected $B d 1$ (T2) to 4 (T3) wk following breeding initiation (Fig. 3), indicating that timing of sampling influences the likelihood of detection. Our results suggest that stratifying sampling across times that coincide with periods of potentially high pathogen prevalence (e.g. following breeding; Table 1) will increase the probability of detection. If data are available, surveyors should plan to sample filters in the days and weeks following times that typically display the highest pathogen prevalence.

Two ponds tested $B d$ positive by one technique and not the other, indicating that in certain contexts one technique can be superior. The single pond that tested $B d$ positive by swabbing and not filtration (McClure Lake; Table 1) had the lowest Bd prevalence $(7 \%$; Table 1$)$ of all the ponds we sampled. Also, only 3 filters (instead of the usual 4) were collected from this pond because it dried before the final sampling period (Table 1). Reduced sample size combined with low $B d$ prevalence may explain why this pond did not test $B d$ positive by filtration. The inability of our filters to detect $B d$ from a low prevalence pond indicates that there may be a threshold $B d$ prevalence (in our case $7 \%$ ) at which filters do not successfully detect this pathogen. Thus, swabbing may be superior to filtering in cases where $B d$ prevalence is low but amphibian hosts are easily captured and/or in high enough abundance to obtain sufficient sample sizes (see Fenichel et al. 2008 and Skerratt et al. 2008 for in-depth treatment of sample sizes and disease detection). On the other hand, filters may be advantageous when amphibian hosts are not abundant. For example, filters identified a pond (No Name 13) as $B d$ positive even though swabs failed to detect $B d$ (Table 1). Only 25 animals (our smallest sample size) were collected from this site. This sample size has a $<95 \%$ probability of detecting $B d$ at prevalences $\leq 11 \%$ (Fenichel et al. 2008). It is apparent that swabbing 25 animals was not sufficient to detect $B d$ at the low prevalence at this pond. Thus, filtering water may be superior when a sufficient number of hosts cannot be collected to detect low levels of $B d$ prevalence by swabbing. Future studies should formally examine the ability of filters to detect $B d$ in areas of low amphibian abundance/low $B d$ prevalence.

The increase in $B d$ detection by filtration following breeding (T2 and T3; Fig. 3) could be a result of the accumulation of $B d$ zoospores in the water following times of high densities of infected and susceptible amphibian hosts (e.g. Vredenburg et al. 2010), such as breeding. This is supported by the positive correlation between $B d$ prevalence in breeding adults and filter detection rates. This is also supported in part by 
the general increase in detected zoospore densities after the initiation of breeding (T1 to T2) followed by a steady decrease in mean zoospores densities after breeding (T2 to T4; Fig. 2), though these differences were not statistically significant. Yet, we found reduced detection by filtration later in the season, when metamorphs emerged (T4), despite the fact that metamorphs emerge at extremely high densities (O. Hyman pers. obs.). This may indicate a reduced density of aquatic $B d$ zoospores due to increases in water temperature or other abiotic factors that change as ponds become warmer and dry out. This reduced detection may also be a result of lowered $B d$ susceptibility in tadpoles or metamorphic froglets (Blaustein et al. 2005). If these stages are not susceptible to $B d$ infection, the number of zoospores released into the environment would be reduced, resulting in decreased rates of detection. Future studies should examine the susceptibility of these life stages to $B d$ infection and the influence of environmental factors such as pond salinity and temperature on disease pathology and $B d$ transmission. We cannot rule out the overall reduction in volume of filtrate at T4 as the cause of reduced detection. However, Walker et al. (2007) found that zoospore densities decreased with increasing volume of filtrate, indicating that more turbid waters often contain higher zoospore densities, though we did not find this trend.

The persistence of $B d$ in the environment can have important implications for host-pathogen dynamics (Mitchell et al. 2008). Although the filtration technique we used cannot distinguish between the presence of live, infectious $B d$ versus non-living (but detectable) $B d$ DNA, the repeated detection of $B d$ in the water column suggests that $B d$ zoospores, or perhaps other life stages, persist in the water column throughout chorus frog Pseudacris maculata development. DNA fragments of approximately 400 base pairs (bp) may persist up to $1 \mathrm{wk}$ at $18^{\circ} \mathrm{C}$ in lake water (Matusi et al. 2001). Also, Dejean et al. (2011) found that bullfrog and sturgeon DNA persist $<1$ mo in pond water. This suggests that the detection of $B d$ throughout our 3 to 4 mo sampling period is from the presence of live zoospores, as opposed to remnant DNA fragments from infected individuals present during the breeding season. However, the reduced detection at T4 does suggest that many of our $B d$ positive filters could be detecting remnant DNA fragments from infected adults (Dejean et al. 2011). Our tests do not allow us to determine the ultimate source of these zoospores (environmental or amphibian hosts); however, reduced $B d$ detection from the water column at the start and the end of the breeding season (Fig. 3) indicates that $B d$ is either not present in the environment in the absence of infected amphibian hosts, or present at much lower densities.

Similar to Walker et al. (2007) and Kirshtein et al. (2007), we found aquatic zoospore densities high enough to cause infections without direct contact with an infected individual (Carey et al. 2006). If these densities represent live infectious zoospores (as opposed to remnant DNA), this could help explain $B d$ 's ability to transmit independent of host density, resulting in local host extinction (Mitchell et al. 2008). Despite these high environmental zoospore densities and high $B d$ prevalence in breeding adults, we found no evidence of disease induced die-offs or local extinctions in the chorus frog populations we studied. Chorus frogs may be tolerant of $B d$ infections or suffering from disease cryptically, after the breeding season, when animals are hidden in the area surrounding ponds.

Filtering small volumes of water $(\leq 600 \mathrm{ml})$ detected $B d$ in small, ephemeral ponds with high $B d$ prevalence. However, $52 \%$ of filters from ponds known to be $B d$ positive falsely tested negative, with the percent of false negatives varying from 31 to $77 \%$ depending on the season. Repeatedly sampling individual ponds at multiple time points (start of breeding, end of breeding, and when tadpoles were present) maximized detection, correctly identifying $94 \%$ of the ponds that swabs designated $B d$ positive. The ideal time to filter water for the presence of $B d$ was at the end of the breeding season and during the following $3 \mathrm{wk}$, when tadpoles were present in ponds. Detection was reduced at the start of breeding and late in the season when metamorphic frogs emerge. These results indicate that filtering water from 3 key time periods in the life cycle of boreal chorus frogs has similar sensitivity to sampling ca. 60 animals across 2 time points. This is encouraging, as there are many advantages to filtering over swabbing. For example, in on-site person-hours, capturing, swabbing, and releasing 60 animals takes significantly longer than filtering ca. $600 \mathrm{ml}$ of water 4 times (O. Hyman pers. obs.). In addition, we estimate a savings of ca. $\$ 330$ (US) in laboratory fees to process 3 water filters versus 60 frogs, per a pond (field-related costs to visit sites not included; calculations available from O. Hyman upon request). These savings could be increased by ending resampling after the first positive result. Had we employed this strategy we would have eliminated an entire sampling event (T4) for all but 3 ponds, and reduced the number of filters processed by ca. $50 \%$. 
However, our results are likely to be host species and even population specific. Researchers will want to conduct similar studies to confirm the sensitivity of water filters in their own system before they incorporate this technique into $B d$ monitoring programs. Given the high percentage of false negatives for filters at any single time point, we do not recommend using this technique for the purpose of determining the presence or absence of $B d$ from areas where little is known about filter sensitivity. We instead recommend a combination of filtering with the swabbing survey recommendations of Skerratt et al. (2008). Combining filtering with animal sampling may be especially worthwhile when amphibian hosts are difficult to capture or in low abundance, as was demonstrated in No Name 13 pond in our study.

Filtering will be most useful for larger scale studies of systems where the dynamics of $B d$ are already relatively well understood and the sensitivity of this technique already assessed. Once the systemspecific sensitivity of this technique is known, then filtering can be used to determine the spatial and temporal distribution of $B d$ on larger scales (e.g. landscapes/years) with much finer resolution at greatly reduced costs. Given the low costs/effort and high potential sensitivity, we recommend this technique be considered for incorporation into long-term $B d$ monitoring initiatives.

\section{CONCLUSIONS}

Sampling small volumes of water can be a viable technique to detect aquatic pathogens such as $B d$. This has now been demonstrated in several systems including ponds (Walker et al. 2007, present study), lakes (Kirshtein et al. 2007), and streams and bromeliads (Cossel \& Lindquist 2009). However, we found that particular attention must be paid to timing and resampling to improve its likelihood of $B d$ detection. We emphasize that our results represent a case study of environmental detection of $B d$ in a metapopulation of a single, seasonally breeding, chorusing amphibian species, with larvae that develop quickly (ca. 3 mo) in small, mostly ephemeral ponds. Given the considerable variation in the habitats, ecology, and natural history of $B d$ 's amphibian hosts, future studies need to examine how the sensitivity of this technique varies across systems with different hosts (e.g. long-lived larvae, continuous breeders, non-seasonal species, non-chorusing species) and habitats (e.g. streams, lakes, rivers, wetlands, bromeliads) before using it as a definitive diagnostic method, as these factors may well influence the likelihood of detecting $B d$ from water samples. Refinement of this technique and recognition of general patterns in $B d$ detectability will help to increase the resolution of $B d$ studies on large spatial and temporal scales, as well as to increase our understanding of $B d$ 's biology outside of focal hosts.

Acknowledgements. We thank Barbara Garcia, Jill Oertly, and the United States Forest Service for providing logistical support, field assistants for filtering water, Crystal Meins for help with PCR analyses and frog drawings, and Angela Picco, Zachary Stahlschmidt, and 2 anonymous reviewers for feedback on earlier drafts. All work was approved by Arizona State University IACUC (09-092R). The present study was funded by Heritage Grant I10018 to O.J.H. and J.P.C. from the Arizona Game and Fish Department.

\section{LITERATURE CITED}

Audemard C, Reece KS, Burreson EM (2004) Real-time PCR for detection and quantification of the protistan parasite Perkinsus marinus in environmental waters. Appl Environ Microbiol 70:6611-6618

Berger L, Speare R, Daszak P, Green DE and others (1998) Chytridiomycosis causes amphibian mortality associated with population declines in the rain forests of Australia and Central America. Proc Natl Acad Sci USA 95: 9031-9036

> Berger L, Hyatt AD, Speare R, Longcore JE (2005) Life cycle stages of the amphibian chytrid Batrachochytrium dendrobatidis. Dis Aquat Org 68:51-63

> Blaustein AR, Romansic JM, Scheessele EA, Han Barbara A, Pessier AP, Longcore JE (2005) Interspecific variation in susceptibility of frog tadpoles to the pathogenic fungus Batrachochytrium dendrobatidis. Conserv Biol 19: 1460-1468

Boyle DG, Boyle DB, Olsen V, Morgan JA, Hyatt AD (2004) Rapid quantitative detection of chytridiomycosis (Batrachochytrium dendrobatidis) in amphibian samples using real-time Taqman PCR assay. Dis Aquat Org 60:141-148

Brinkman NE, Haugland RA, Wymer LJ, Byappanahalli M, Whitman RL, Vesper SJ (2003) Evaluation of a rapid, quantitative real-time PCR method for enumeration of pathogenic Candida cells in water. Appl Environ Microbiol 69:1775-1782

> Carey C, Bruzgul JE, Livo LJ, Walling ML and others (2006) Experimental exposures of boreal toads (Bufo boreas) to a pathogenic chytrid fungus (Batrachochytrium dendrobatidis). EcoHealth 3:5-21

Collins JP, Crump M (2009) Extinction in our times: global amphibian decline. Oxford University Press, New York, NY

Cossel JO, Lindquist ED (2009) Batrachochytrim dendrobatidis in arboreal and lotic water sources in Panama. Herpetol Rev 40:45-47

Daszak P, Cunningham AA, Hyatt AD (2000) Emerging infectious diseases of wildlife-threats to biodiversity and human health. Science 287:443-449

Dejan T, Valentini A, Duparc A, Pellier-Cuit S, Pompanon F, Taberlet P, Miaud C (2011) Persistence of environmental DNA in freshwater ecosystems. PLoS One 6:e23398 
Epstein PR (1993) Algal blooms in the spread and persistence of cholera. Biosystems 31:209-221

Fenichel EP, Tsao JI, Jones MJ, Hickling GJ (2008) Fish pathogen screening and its influence on the likelihood of accidental pathogen introduction during fish translocations. J Aquat Anim Health 20:19-28

USFWS (US Fish and Wildlife Service) (2007) Chiricahua leopard frog (Rana chiricahuensis) recovery plan. USFWS, Southwest Region, Albuquerque, NM

Garland S, Baker A, Phillott AD, Skerratt LF (2010) BSA reduces inhibition in a TaqMan ${ }^{\circledR}$ assay for the detection of Batrachochytrium dendrobatidis. Dis Aquat Org 92: 113-116

Garner TW, Walker S, Bosch J, Leech SJ and others (2009) Life history tradeoffs influence mortality associated with the amphibian pathogen Batrachochytrium dendrobatidis. Oikos 118:783-791

Greer AL, Collins JP (2007) Sensitivity of a diagnostic test for amphibian ranavirus varies with sampling protocol. J Wildl Dis 43:525-532

Hyatt AD, Boyle DG, Olsen V, Boyle DB and others (2007) Diagnostic assays and sampling protocols for the detection of Batrachochytrium dendrobatidis. Dis Aquat Org 73:175-192

Kirshtein JD, Anderson CW, Wood JS, Longcore JE, Voytek MA (2007) Quantitative PCR detection of Batrachochytrium dendrobatidis DNA from sediments and water. Dis Aquat Org 77:11-15

Kramer DC (1973) Movements of western chorus frogs Pseudacris triseriata triseriata tagged with $\mathrm{Co}^{60}$. J Herpetol 7:231-235

Kriger KM, Hero JM, Kevin JA (2006) Cost efficiency in the detection of chytridiomycosis using PCR assay. Dis Aquat Org 71:149-154

Loge FJ, Thompson DE, Call DR (2002) PCR detection of specific pathogens in water: a risk-based analysis. Environ Sci Technol 36:2754-2759

Matsui K, Honjo M, Kawabata Z (2001) Estimation of the fate of dissolved DNA in thermally stratifield lake water from

Editorial responsibility: Cynthia Carey,

Boulder, Colorado, USA the stability of exogenous plasmid DNA. Aquat Microl Ecol 26:95-102

Mitchell KM, Churcher TS, Garner TW, Fisher MC (2008) Persistence of the emerging pathogen Batrachochytrium dendrobatidis outside the amphibian host greatly increases the probability of host extinction. Proc Biol Sci 275:329-334

Pfeiffer D (2002) Veterinary epidemiology - an introduction. Royal Veterinary College, University of London, London

Retallick RWR, Miera V, Richards KL, Field KJ, Collins JP (2006) A non-lethal technique for detecting the chytrid fungus Batrachochytrium dendrobatidis on tadpoles. Dis Aquat Org 72:77-85

Saah AJ, Hoover DR (1997) 'Sensitivity' and 'specificity' reconsidered: the meaning of these terms in analytical and diagnostic settings. Ann Intern Med 126:91-94

Skerratt LF, Berger L, Speare R, Cashins S, McDonald KR, Phillot AD, Hines HB, Kenyon N (2007) Spread of chytridiomycosis has caused the rapid global decline and extinction of frogs. EcoHealth 4:125-134

Skerratt LF, Berger L, Hines HB, McDonald KR, Mendez DR, Speare R (2008) Survey protocol for detecting chytridiomycosis in all Australian frog populations. Dis Aquat Org 80:85-94

Spalding MG, Forrester DJ (1993) Disease monitoring of free-ranging and released wildlife. J Zoo Wildl Med 24: $271-280$

Voyles J, Young S, Berger L, Campbell C and others (2009) Pathogenesis of chytridiomycosis, a cause of catastrophic amphibian declines. Science 326:582-585

Vredenburg VT, Knapp RA, Tunstall TS, Briggs CJ (2010) Dynamics of an emerging disease drive large-scale amphibian population extinctions. Proc Natl Acad Sci USA 107:9689-9694

Walker SF, Baldi Salas M, Jenkins D, Garner TW and others (2007) Environmental detection of Batrachochytrium dendrobatidis in a temperate climate. Dis Aquat Org 77: 105-112

Submitted: June 24, 2011; Accepted: October 31, 2011

Proofs received from author(s): January 13, 2012 